Ecos de la Revolución de octubre en España a tráves del viaje de Chaves Nogales a la Unión Soviética $M^{\mathrm{a}}$ Magdalena Garrido Caballero

Anuario № 29 / ISSN 1853-8835 / pp. 64-85 /2017

http://anuariodehistoria.unr.edu.ar/ojs/index.php/Anuario/index

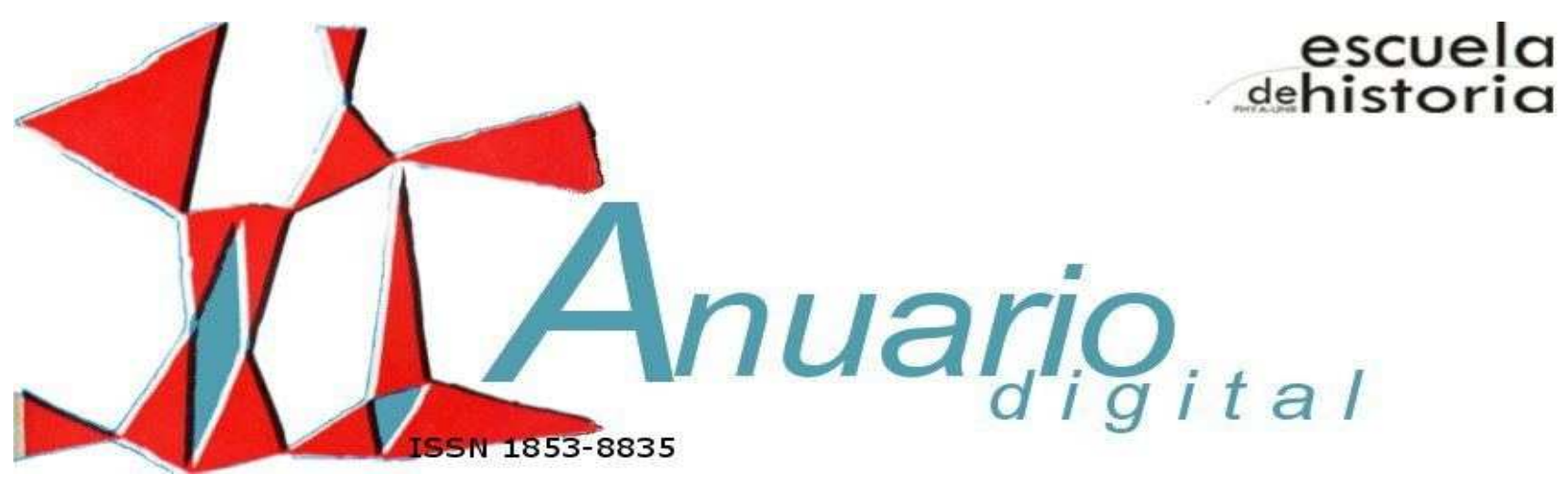

Ecos de la Revolución de Octubre en España a tráves del viaje de Chaves Nogales a la Unión Soviética

Echo of the revolution of October in Spain through the trip the Chaves Nogales to the Soviet Union

Ma MAGDALENA GARRIDO CABALLERO*

(Universidad de Murcia); España

mgarridocaballero@um.es

RESUMEN

El objetivo de este artículo es abordar el impacto de la Revolución de Octubre en España a través de los estudios académicos que reflexionan sobre este hecho y la experiencia soviética, sintetizando las principales líneas discursivas. Con este fin se utilizan como fuentes principales la aportación de especialistas en la materia, y se analizan, a modo de estudio de caso, las impresiones del escritor Manuel Chaves Nogales, como observador directo de la Unión Soviética, a través de un viaje realizado en 1928. Su testimonio cobra actualidad para reflexionar sobre la imagen de unos países en otros, máxime en el contexto del centenario de un hecho histórico que marcó el siglo XX.

\footnotetext{
* Profesora del Área de Historia Contemporánea en la Facultad de Letras, Universidad de Murcia. Este texto se integra en el marco del proyecto Hispanofilia III. REF. HAR2014-52414-C2-1-P.

Esta obra está sujeta a la Licencia Reconocimiento-NoComercial-Compartirlgual 4.0 Internacional de Creative Commons. http://creativecommons.org/licenses/by-nc-sa/4.0/ 


\section{Ecos de la Revolución de octubre en España a tráves del viaje de Chaves Nogales a la Unión Soviética}

Palabras clave: Revolución de Octubre; percepciones sobre la Unión Soviética; historiografía; siglo XX; Chaves Nogales.

ABSTRACT

The aim of this article is to show the impact of the October Revolution in Spain through studies based on the Revolution and Soviet experience, and the main discursive lines in the transmission of this historical event. To this end, the contribution of scholars and Manuel Chaves Nogales' perceptions on the Soviet Union, where travelled in 1928, are analyzed in order to approach the image of October Revolution in Spain. His testimony comes to light to reflect on the image of some countries in others, especially in the context of the centennial of a historical event that marked the twentieth century.

Keywords: October Revolution; perceptions on the Soviet Union; historiography; 20th Century; Chaves Nogales.

\section{Introducción}

La Revolución rusa de Octubre de 1917 tuvo su impronta entre sus contemporáneos a través de crónicas periodísticas ${ }^{1}$ y libros de viaje $^{2}$. No obstante, la divulgación de este acontecimiento revolucionario contó con una serie de dificultades en España como la carestía de papel, la rivalidad con otras noticias de índole interna, una sección internacional, marcada por la Primera Guerra Mundial, y el grado de fiabilidad de las noticias bajo el filtro de la censura, máxime en momentos álgidos a raíz de la huelga general de $1917^{3}$.

El común denominador de la mayoría de los primeros escritos sobre la Rusia soviética ha sido la influencia del propio contexto político en España y la ideología de los autores, concitando visiones contrapuestas. Por un lado, generó expectativas derivadas de los logros revolucionarios, "la fe que vino

\footnotetext{
${ }^{1}$ Lazo Díaz, Alfonso; La Revolución Rusa en el diario ABC de la época; Secretariado de Publicaciones de la Universidad de Sevilla; Sevilla; 1975. Blanco García, Carmen; "Sofía Casanova e Emma Goldman na revolución rusa" en Pazos, Antón M.; Vida e tempo de Sofía Casanova (1861-1958); 2010; pp. 115-133. Vázquez Liñán, M.; La Revolución y la Guerra civil rusa en “El maestro Juan Martínez que estaba alli"; en Bellido, P. y Cintas, Ma I. (Coords); Manuel Chaves Nogales, una aproximación; 2009; pp. 65-83. Desde la fotografía, véase Sánchez Pita, Fernando; “El viaje que retrató a la Rusia de 1917"; Archivamos: Boletín ACAL; 87; 2013; pp. 47-48.

${ }^{2}$ Sanz Guitián, Pablo; Viajeros españoles en Rusia; Compañía Literaria; Madrid; 1995.

${ }^{3}$ Almuiña, Celso J.; “La imagen de la Revolución rusa en España”; IH; 17 ; 1997; p.217.
}

65

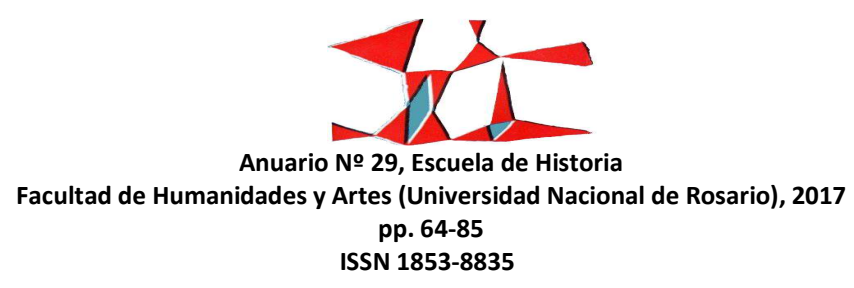


del Este" ${ }^{\prime 4}$, dentro del movimiento obrero, los futuros partidos comunistas y asociaciones financiadas por la Komintern, por otro, se identificó con el "Terror rojo" o "anticristo", ante el miedo de contagio revolucionario de la experiencia bolchevique en la Europa de Entreguerras, y se asoció al marxismo con la barbarie en el pensamiento tradicionalista y filofascista ${ }^{5}$.

En el ámbito académico, y a modo de panorámica de los estudios realizados sobre la Revolución de Octubre de 1917 en España, síntesis que dista de ser exhaustiva y se centra principalmente en la labor desplegada por historiadores, han destacado los trabajos de Antonio Fernández García, Fernando Díez del Corral, Armanda Rodríguez Fierro, Juan Avilés Farré, Ricardo Martín de la Guardia y más recientemente Juan Andrade y Fernando Hernández ${ }^{6}$. Entre los temas más abordados hay que destacar la influencia de Octubre en el movimiento obrero y especialmente del nominado "trienio bolchevique"7, la formación del $\mathrm{PCE}^{8}$, siendo significativos los estudios de Rafael Cruz y Fernando Hernández, y la influencia soviética en la política española en el marco de las relaciones internacionales, destacándose para el periodo republicano las aportaciones de Ángel Luis Viñas, entre otros autores ${ }^{9}$.

\footnotetext{
${ }^{4}$ Avilés, Juan; La fe que vino de Rusia; UNED; Madrid; 1999.

${ }^{5}$ Egido, Ma Ángeles; “Del paraíso soviético al peligro marxista: La Unión Soviética en la España republicana (1931-1936)"; Cuadernos de Historia Contemporánea; 10 ;1988; pp. 139-154.

${ }^{6}$ Díez, F.; La revolución rusa; Anaya; Madrid; 1991; también autor de Lenin. Una biografía; El viejo Topo; Madrid; 1999. Fernández, A.; La Revolución Rusa; Istmo; Madrid; 1990. Rodríguez, A.; La revolución rusa y el desarrollo de la URSS; Akal; Madrid; 1991. Martín, R. M.; "La revolución soviética y su impacto internacional. La URSS 1917-1929"; en Pereira, J.C. (Coord.). Historia de las relaciones internacionales contemporáneas; Ariel; Barcelona; 2001; pp 263-279. Carantoña, Francisco y Puente, Gustavo (Eds); La Revolución Rusa 70 años después: Actas del Segundo Coloquio de Historia Contemporánea; Universidad de León, León; 1988. Pelloile, Manuelle; "La imagen de la Revolución Rusa en España: amplificación y permanencias años veinte-noventa del siglo XX"; en Civil, P. y Crémoux, F. Actas del XVI Congreso de la Asociación Internacional de Hispanistas: Nuevos caminos del hispanismo; París, del 9 al 13 de julio de 2007; Vol. 2; 2010. Andrade, J. y Hernández, F. (eds); 1917. La Revolución rusa cien años después; Akal; Madrid; 2017.

${ }^{7}$ Forcadell, C. y Carreras Ares, J. J.; Parlamentarismo y bolchevización: el movimiento obrero español, 1914-1918; Crítica; Barcelona; 1978. Paniagua Fuentes, F. J.; "Las repercusiones de la revolución rusa en el movimiento libertario español"; Anales del centro de Alzira de la UNED, 1; 1980); pp 61-88. Trinidad Pérez, Francisco; El Movimiento Obrero en la provincia de Cádiz (1914-1923); Universidad de Cádiz; Cádiz; 1998. Romero, F.; The Foundations of Civil War. Revolution, Social Conflict and Reaction in Liberal Spain, 1916-1923; Cañada Blanch Centre; London; 2008.

${ }^{8}$ Meaker, Gerald H.; La izquierda revolucionaria en España 1914-1923; Ariel; Barcelona; 1978. Cruz, R.; El Partido Comunista de España en la II República; Alianza; Madrid; 1987. Pérez Ledesma, M. y Cruz, R.; Cultura y movilización en la España contemporánea; Alianza; 1997. Elorza, Antonio y Bizcarrondo, Marta; Queridos camaradas. La Internacional Comunista y España; Planeta; Barcelona; 1999. Hernández, F.; Guerra o revolución. El partido comunista de España en la Guerra Civil; Crítica, Barcelona; 2010.

9 San Román Sevillano, A.; Los amigos de la Unión Soviética (AUS) [Microforma]: propaganda política en España (1933-1938); Ediciones Universidad de Salamanca; Salamanca; 1994. Vázquez, M.; Propaganda y política de la Unión Soviética en la Guerra Civil Española (1936-1939); Universidad Complutense de Madrid; Madrid; 1999. Kowalsky, D.; La Unión Soviética y la guerra civil española: una revisión crítica; Crítica; Barcelona; 2004. Viñas, Á.; El escudo de la República. El oro de España, la apuesta soviética y los hechos de mayo de 1937; Crítica; Barcelona; 2007 y El honor de la República. Entre el acoso fascista, la hostilidad británica y la
}

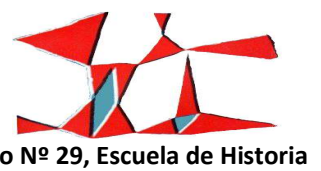

Facultad de Humanidades y Artes (Universidad Nacional de Rosario), 2017

pp. 64-85

ISSN 1853-8835 


\section{Ecos de la Revolución de octubre en España a tráves del viaje de Chaves Nogales a la Unión Soviética}

En la labor del conocimiento sobre los países de Europa del Este han sido relevantes los encuentros académicos, organizados por Carlos Flores Juberías, y los monográficos publicados ${ }^{10}$, así como la labor desempeñada por la revista Cuadernos del Este, continuada por Papeles del Este, suponiendo un salto cualitativo en el plano historiográfico español, deudor de las obras foráneas. También hay que subrayar el papel de los corresponsales de los medios de comunicación que, in situ, han arrojado una visión más próxima a la realidad en sus crónicas aportando fuentes a los historiadores.

En el ámbito historiográfico, se publicaron las reflexiones en torno a La Revolución Rusa, 70 años después, sobre las que se centró el Segundo Coloquio de Historia Contemporánea, celebrado en la Universidad de León en colaboración con la Universidad de Voronezh. La primera parte de esta obra gira en torno a la Revolución de Octubre de 1917 y la formación de la Unión Soviética, destacándose el papel de la intelectualidad obrera y su alianza con la masa proletaria para explicar el triunfo de la revolución, al sentir como propias las ideas de los bolcheviques; el análisis de la constitución de 1918 y el sistema educativo, aunque con más alusiones a los cambios propiciados por la Perestroika, que marcaba la actualidad en la URSS, que al pasado. Otras contribuciones versaron sobre figuras como Lenin y Trotsky. En la segunda parte, se presta atención a la recepción de Octubre en el extranjero, destacando la aportación de J. J. Carreras Ares sobre la escasez de textos historiográficos hasta después de la Segunda

Guerra Mundial ${ }^{11}$. Es decir, el momento de apogeo de los estudios sobre la Unión Soviética coincidiría con la guerra fría. Y, una vez cayó la Unión Soviética, los estudios acerca de las interpretaciones sobre la Revolución Octubre y el sistema soviético proliferaron, destacándose las aportaciones de Carlos Taibo, Jesús de Andrés, entre otros especialistas ${ }^{12}$.

política de Stalin; Crítica; Barcelona; 2008. Garrido, M.; Compañeros de viaje. Historia y memoria de las Asociaciones de Amistad Hispano-Soviéticas; Editum; Murcia; 2009.

${ }^{10}$ Entre 1998 y 1999 encabezó el proyecto de investigación “Hacia la consolidación de un Estado de Derecho en la Europa del Este: Balance y perspectivas". Y entre 1998 y 2006 fue el coordinador general de los cinco primeros Encuentros Españoles de Estudios sobre la Europa Oriental.

${ }^{11}$ Carantoña, F., Fuente, G. (Eds.); La Revolución Rusa 70 años después: Actas del segundo coloquio de Historia Contemporánea; Universidad de León; León; 1988.

12 Entre las obras de Taibo que abordan toda la andadura la Unión Soviética destacan De la Revolución de octubre a Gorbachov. Una aproximación a la Unión Soviética; Libros de la Catarata; Madrid; 1991; La Unión Soviética; Síntesis; Madrid; 1993. Por su parte, Jesús de Andrés se ha centrado en proyectos diversos sobre el sistema político soviético y la Rusia postsoviética como "Autoritarismo y neopatrimonialismo en el espacio postsoviético: dinámicas internas e influencia exterior" del Ministerio de Ciencia e Innovación. Y entre sus obras ha publicado junto a M. Flores el Atlas Ilustrado del Comunismo; Susaeta editores; Madrid; 2007; "En torno a la transición Soviético-Rusa"; Papeles del Este: Transiciones poscomunistas; 1; 2011.

67

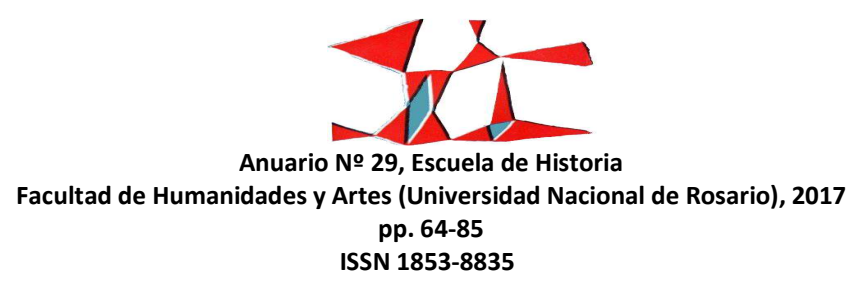


En un ejercicio de síntesis, el historiador Antonio Fernández García distinguió las siguientes corrientes en la que podían enmarcarse los trabajos realizados: la versión "liberal" de contemporáneos como Miliukov o Kerenski, redujo la revolución de Octubre a un golpe de Estado que interrumpió la evolución hacia una democracia occidental. El historiador español Jesús Pabón se inscribiría en esta corriente $^{13}$. Mientras que Carlos Hermida ofrece una visión contraria a reducir la Revolución a un golpe de Estado, insistiendo en su componente social ${ }^{14}$, en la línea de la versión "optimista", que contempla la revolución como obra de un partido y su proyecto de modernización, y presenta la etapa estalinista como una ruptura. Esta corriente tuvo en la propia URSS su correlato tras la muerte de Stalin en la obra de Mints, Istoriia Velikogo Oktiabria (1967-1972) y en la biografía de Lenin (1973). En la visión "revisionista" se establece la continuidad entre Lenin y Stalin en la encarnación de un mismo proyecto y arrojan cifras menos elevadas en relación al volumen de represaliados. Mientras que la corriente "crítica", que aglutina un mayor número de estudios, señala al modelo soviético como totalitario, con Stalin como su exponente más cruento, pero hundiendo sus raíces en la etapa precedente ${ }^{15}$. En 2017, J. Fontana reflexionaba sobre la significación de Octubre subrayando las dificultades para llevar a efecto la transición hacia una sociedad comunista, en base a lo postulado por Lenin en Estado y Revolución (1917), así como las dificultades en un clima de combate contra las ideas que habían inspirado la revolución y sus grupos partidarios a escala mundial; y considerando que Octubre todavía tiene eco en el presente por la crisis internacional y en los proyectos alternativos transnacionales ${ }^{16}$.

Los debates acerca de la Revolución, naturaleza del Estado soviético, su proyecto y evolución han sido enriquecedores en el plano historiográfico y lo siguen siendo como prueba la última obra de Julián Casanova dedicada a esta cuestión, señalando que lo que acaba con la autocracia zarista no son solamente factores internos como la movilización interior, el hambre o la incapacidad absoluta del zar, sino externos como la participación en la I Guerra Mundial y la disolución del imperio, "las revoluciones de 1917 ya no son políticas o ideológicas o de clase, sino que incluyen también elementos nacionales o, si se quiere, nacionalistas" ${ }^{17}$. Asimismo destaca el papel de las mujeres en las movilizaciones desde febrero de 1917. Sin

\footnotetext{
${ }^{13}$ Pabón, J.; Bolchevismo y literatura. La novela soviética en sus creaciones típicas; Madrid; 1949.

${ }^{14}$ Hermida, C.; La revolución bolchevique no fue un golpe de Estado; Historia y Comunicación Social; 7 ; 2002; pp.109-119.

${ }^{15}$ Fernández, A.; "Auge y caída del comunismo"; Cuadernos de Historia Contemporánea, 21; 1999; pp 107-146.

${ }^{16}$ Fontana, J.; "la Revolución Rusa y nosotros"; Nuestra Historia, 2; 2016; pp. 155-163. Autor del libro El siglo de la revolución. Una historia del mundo desde 1914; Crítica; Barcelona; 2017.

${ }^{17}$ Casanova, J.; La venganza de los siervos; Crítica; Barcelona; 2017. Recogido en El Cultural, 10 de enero de 2017.
}

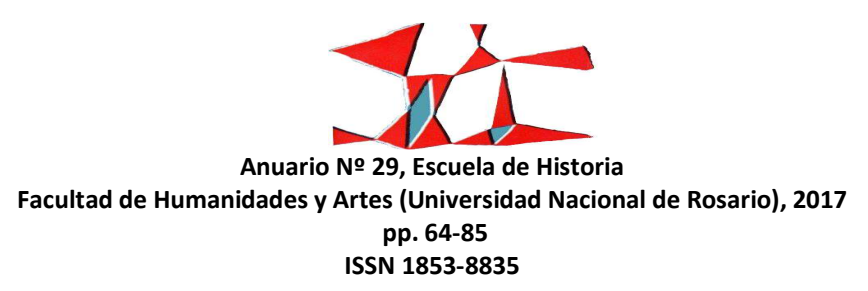




\section{Ecos de la Revolución de octubre en España a tráves del viaje de Chaves Nogales a la Unión Soviética}

duda, un avance sobre la puesta al día en los estudios referidos al centenario de la Revolución de Octubre supondrá el congreso internacional "La Revolución Rusa y su lugar en el siglo XX", organizado por el Instituto de Historia Universal de Academia de las Ciencias de Rusia, Moscú, 27 - 28 de septiembre de 2017 y “El centenario de la Revolución Rusa (1917-2017)", que tendrá lugar en la Universidad de Barcelona, el 25-27 de octubre de 2017, entre otros encuentros científicos.

En este artículo se presta especial atención a las realizaciones de la Revolución de Octubre de 1917 proyectadas en España a través de las crónicas de Chaves Nogales, como un estudio de caso de la visión de la URSS en los años veinte ${ }^{18}$. El periodista Manuel Chaves Nogales viajó por Europa en avión entre agosto y noviembre de 1928. Fruto de las experiencias vividas en este viaje fueron los reportajes que aparecieron en el Heraldo de Madrid (con cobertura económica e imágenes en primera plana) hasta su colofón el 30 de noviembre de $1928^{19}$. Un año más tarde, fueron publicados en formato libro con el título La vuelta a Europa en avión. Un pequeño burgués en la Rusia roja por la editorial Mundo Latino, se incluyeron algunos fragmentos, sin censura, y algunos artículos inéditos. Esta obra, en un intento de realizar una crónica desapasionada de la URSS, contiene una imagen que, sin de dejar de ser una apreciación subjetiva de lo observado en territorio soviético, contrasta con las visiones militantes de la época por su ecuanimidad.

En abril de 1931 se proclamó en España la Segunda República, contexto democrático en el que florecieron los contactos con la Unión Soviética y también los discursos contrapuestos. En plena guerra civil, se celebró el vigésimo aniversario de la Revolución bolchevique en zonas bajo control republicano, dibujándose la URSS como aliada pero también como enemiga interventora entre los sectores de apoyo a la sublevación de julio de 1936. La labor desplegada de manera colectiva por los Amigos de la Unión Soviética (organización constituida en España en 1933) adquirió otra dimensión en tiempos de guerra, pues realizó una aproximación idealista de la Unión Soviética, de su ayuda al Frente Popular, y expandió un discurso antifascista que tuvo predicamento entre los combatientes y la población, visión que fue secundada por otras asociaciones de amistad con la Unión Soviética en el extranjero, que durante toda su andadura defendieron la política soviética. Hasta 1956, grosso modo, la Revolución y sus realizaciones tuvieron un

\footnotetext{
${ }^{18}$ Sevilla, 7 de agosto de 1897 - Londres, 1944. Véase para un perfil biográfico y edición crítica de sus obras: VV. AA.; El periodista comprometido. Manuel Chaves Nogales. Una aproximación; Facultad de Comunicación y Centro de Estudios Andaluces; Sevilla; 2009.

${ }^{19}$ Heraldo de Madrid, 30 de noviembre de 1928.
}

69

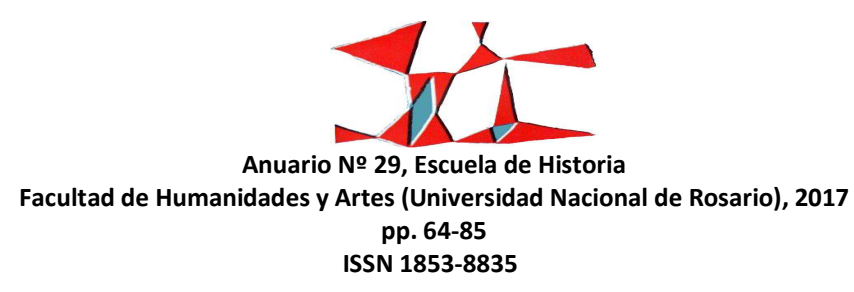


amplio predicamento entre los intelectuales de izquierda. La intervención soviética en Hungría en 1956 y la de Checoslovaquia en1968 hicieron mella, al igual que las obras fruto del desencanto con el sistema soviético. Así, Vida y muerte en la URSS de Valentín González, Yo fui un ministro de Stalin de Jesús Hernández, publicadas fuera de España, tuvieron por su contenido crítico acogida favorable en la dictadura franquista, que desarrolló un discurso anticomunista en las publicaciones oficiales y noticiarios como el NODO. En los años marcados por la guerra fría tanto la propaganda antisoviética como la favorable a la URSS redoblaron sus esfuerzos para mostrar las bondades de un modelo y denostar al contrario. Prevaleció en España una imagen negativa del modelo soviético y en la URSS del modelo capitalista, al tiempo que se mantuvo en un segundo plano los contactos vía terceros países y el intercambio comercial entre ambos países. En síntesis, las sociedades de uno y otro lado del telón de acero fueron víctimas de la manera en la que los hechos fueron contados. De ahí la importancia de los testimonios directos que se aproximaron o, al menos, lo procuraron, sin juicios preconcebidos.

\section{La Rusia Soviética de los años 20 a través de La vuelta a Europa en avión. Un pequeño burgués en la Rusia roja (1929)}

Los acontecimientos revolucionarios en Rusia tuvieron eco en España, prueba de ello es un incremento de obras referidas a la Unión Soviética, incluyendo la reedición de obras en las editoriales españolas proclives a la "literatura de avanzada", caracterizada por un componente más social. Según Martínez Rus, este movimiento de renovación editorial surgió como respuesta al estricto sistema de censura previa impuesto a las publicaciones periódicas durante la dictadura del militar Miguel Primo de Rivera ${ }^{20}$, pero tolerante con el libro, siempre que superase las doscientas páginas, ya que por extensión y precio, resultaban inalcanzables para el conjunto de ciudadanos. Así aparecieron Ediciones Oriente (1928-1932) ${ }^{21}$ e Historia Nueva (1928-1931) ${ }^{22}$, sociedades complementarias y de escasos recursos económicos ${ }^{23}$. Ediciones

\footnotetext{
20 Dictadura que abarcó de 1923 a 1930, tras su dimisión, continuó al frente R. Berenguer, hasta la proclamación de la Segunda República en 1931.

${ }^{21}$ Ediciones Oriente surge en esta coyuntura por la iniciativa de Joaquín Arderius y R. Giménez Siles que la instalaron en la imprenta Argis, mientras que Juan Andrade hizo las veces de director literario y José Venegas fue gerente en su primera etapa. La editorial se especializó en literatura extranjera, teniendo en cuenta la alternativa política y social que la Unión Soviética representaba frente a los países capitalistas; apostando por un compromiso de la literatura frente a la deshumanización del Arte.

${ }^{22}$ Especializada en autores españoles e hispanoamericanos.

${ }^{23}$ Santonja, G.; Del lápiz rojo al lápiz libre. La censura de prensa y el mundo del libro; Barcelona; 1986.
}

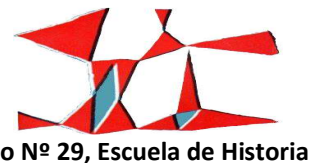




\section{Ecos de la Revolución de octubre en España a tráves del viaje de Chaves Nogales a la Unión Soviética}

Oriente, impulsada por los promotores de la revista Post-Guerra (Madrid 1927-28)24, boletín pacifista y de inquietudes revolucionarias, tenía como obras de referencia las de contenido político y social. La gran acogida que tuvo el servicio de librería que recogía libros de las editoriales Biblios y Antorcha, próximas al Partido Comunista, impulsó a la edición de libros. Por su parte, la Compañía Iberoamericana de Publicaciones (CIAP), creada en 1928, logró la rápida distribución de sus títulos con una organización comercial amplia y moderna (tenía la exclusiva en España e Hispanoamérica de fondos de otras editoriales como Zeus, Ulises...) y además aglutinaba editoriales como Mundo Latino (así como Atlántida, Renacimiento, Fe, Estrella.... $)^{25}$, que publicó las crónicas de Chaves Nogales, objeto de análisis en este artículo. De este modo llegaban novedades a pequeñas librerías ${ }^{26}$.

Por tanto, lo que acontecía en la Rusia soviética concitaba interés y los textos políticos que sortearon la censura llegaron a los lectores españoles. Hay que tener en cuenta que no hubo un reconocimiento del Estado soviético por parte de España en las primeras décadas de su andadura hasta 1933. Los comentarios de admiración por los avances conseguidos en la URSS no estaban reñidos con las críticas hacia otros aspectos de la dictadura del proletariado y la praxis política en obras como las del anarquista Ángel Pestaña, el socialista Fernando de los Ríos, cuyos partidos no se sumaron a la Internacional Comunista o la del notario Diego Hidalgo, desde una óptica liberal ${ }^{27}$. En el ámbito jurídico se destacan las obras de especialistas del derecho penal en las que se describían los cambios legales en la URSS ${ }^{28}$. Del

\footnotetext{
24 Post-Guerra ofrecía a sus lectores, incluso en los pueblos más recónditos, títulos de pensamiento político y de literatura social como La caballería roja de Babel, Los de abajo de Azuela, o Barbas de estopa de Dostoievski en ediciones al módico precio de 90 céntimos, mientras en las librerías se vendían a 4 y 5 pesetas. También difundieron el Manifiesto Comunista a 50 céntimos. Asimismo enviaban publicaciones a los domicilios asumiendo los gastos de obras como El abc del comunismo de Bujarin a 3,50 pesetas, El Capital a 5 pesetas y los dos tomos de la novela Encadenamientos de Barbusse a 8 pesetas. Para más información véase: Martínez Rus, A. Mạ; La política del libro sobre la Segunda República: socialización de la lectura; Universidad Complutense de Madrid; Madrid; 2001; p. 424.

25 Mundo Latino se especializó en ensayos y traducciones de obras extranjeras. Véase para más información el Catálogo de publicaciones de la CIAP; Madrid; 1930; pp. 13-21; Ibídem; p. 244.

${ }^{26}$ En 1931, la quiebra de la Banca Bauer y Cía., su socio capitalista, que obligó a la CIAP a declarar suspensión de pagos. Para más información véase Santonja, G.; La República de los libros. El nuevo libro popular de la Il República; Barcelona; 1989: pp. 14-25.

27 Pestaña, Á.; Setenta días en Rusia. Lo que yo vi; Tipografía Cosmos; Barcelona (s.f.). Hidalgo, D.; Un notario español en Rusia; Alianza; Madrid; 1985. Publicado por primera vez en 1929 por la editorial Cénit; De Los Ríos, F.; Mi viaje a la Rusia sovietista; Alianza; Madrid; 1970. Véase Garrido, M.; Compañeros de viaje. Historia y memoria de las asociaciones de amistad; Editum; Murcia; 2009.

${ }^{28}$ Cuello Calón, E.; El Derecho Penal de la Rusia Soviética seguido del Código penal ruso de 1926; Clarasó; Barcelona; 1931; El Derecho Penal de las dictaduras (Rusia, Italia, Alemania); Clarasó; Barcelona; 1934. De Castro, H.; Principios de derecho soviético; Editorial Reus; 1934. Jiménez de Asúa, L.; El nuevo Códiqo penal de la Rusia soviética [precedido de un estudio preliminar por el profesor M. Grodsinsky; traducción directa de los manuscritos alemanes por Luis Jiménez de Asúa y José Arturo Rodríguez Muñoz; prólogo de L. Jiménez de Asúa]; Reus-Madrid; 1927. Jiménez de Asúa, L.; La vida penal en Rusia: Las leyes penales y reformadoras de la Rusia
}

71

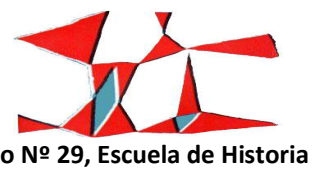

Facultad de Humanidades y Artes (Universidad Nacional de Rosario), 2017

pp. 64-85

ISSN 1853-8835 
análisis del código soviético de 1926 se deduce la imposición del "espíritu de clase", un código punitivo con penas rigurosas por delito ideológico. De ahí que determinados aspectos del modelo de progreso soviético quedaban relegados a la confianza en la enmienda de sus fallos, ya que de los análisis científicos se desprendían críticas. Todas estas visiones contemporáneas a la ofrecida por Chaves Nogales son una pequeña muestra de la diversidad de impresiones y enfoques ideológicos sobre la realidad soviética, aparte de la posición oficial del gobierno español respecto a la URSS, de la que los diplomáticos informaban a través de terceros países.

Respecto al autor de Viaje a Europa..., Chaves Nogales ha sido un periodista 'rescatado del olvido' como prueba la reedición de sus obras, dado que fue "un perdedor entre los perdedores" en el exilio republicano, a Francia primero, donde dio cuenta de la ocupación nazi, y en Reino Unido después, donde falleció en 1944. No obstante, algunas de sus obras han tenido mayor reconocimiento, caso de $A$ sangre $y$ fuego (sobre la guerra civil española, publicado en Chile en 1937). Sus crónicas cobran sentido en el centenario de la Revolución, teniendo en cuenta que en su momento, como ya se ha señalado, la I Guerra Mundial y los asuntos internos primaron, así como los efectos de la censura. El interés en los cambios sucedidos en la URSS se materializó en obras, a raíz de los viajes y contactos establecidos en los años veinte, como documentó la investigación de Vera Kuleshova ${ }^{29}$. Chaves Nogales dedicó varios libros a la Rusia Soviética ${ }^{30}$, en el seleccionado, reeditado en 2012, recoge múltiples facetas del régimen soviético y especialmente se hace eco de los cambios en la sociedad. Rusia era descrita por Chaves Nogales como una "nación adolescente", dado que su modelo tan sólo había cumplido una década, tras una Revolución y guerra civil que causaron estragos. Sin embargo, consideraba, a la altura de 1928, improbable una involución del sistema político por los cambios que se habían producido y el calado de los mismos. En el análisis de esta obra se presta especial atención a los aspectos más destacados de sus impresiones acerca de la Unión Soviética, los contrastes de su modelo de progreso, el choque generacional, así como la represión política y algunas referencias culturales sobre la censura en los medios de comunicación, que se detallan a continuación en distintos epígrafes.

soviética [Luis Jiménez de Asua. M. Grodzinsky, J. Arturo Rodríguez Muñoz, M. Figueroa Román]; Madrid; 1931. Ruiz-Funes, M.; El derecho penal de los soviets [prólogo de Osvaldo Loudet]; Buenos Aires; Revista de Criminología, Psiquiatría y Medicina Legal; 1929.

${ }^{29}$ Kuleshova, V.; Ispania y SSR; Moskva; 1977.

${ }^{30}$ La vuelta a Europa en avión; Mundo Latino; 1929; El maestro Juan Martínez que estaba alli; La bolchevique enamorada; Asther; Barcelona; 1930; Lo que ha quedado del imperio de los zares; s.l., 1931.

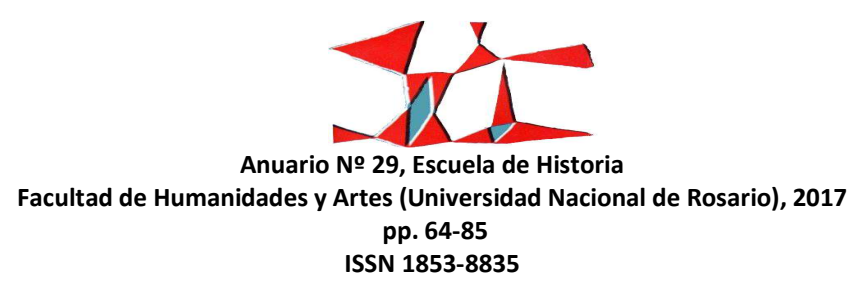




\subsection{La URSS, un modelo con luces y sombras}

Sobrevolando de Letonia a Rusia, Chaves Nogales describe el paisaje caracterizado por su extenso hábitat rural y la escasa densidad demográfica del territorio soviético en comparación con otros países europeos: "El campesino ruso vive sobre el campo, a solas con él, sin ningún contacto con la ciudad, sin formar siquiera esos pequeños núcleos urbanos que son los pueblos agrícolas de Europa" ${ }^{31}$, sorteado de isbas e iglesias. En cambio, otros campesinos rompían con este medio y emprendían un éxodo rural hacia las ciudades para sumarse a la producción industrial, no encontrando ni el apoyo ni el sostén necesario:

"Esas masas de emigrantes del campo a la ciudad que yo he visto perdidas por las calles de Moscú en busca de trabajo, con sus petates mugrientos a la espalda, durmiendo a la intemperie, viviendo del pillaje y la mendicidad, no tienen indudablemente derecho al trabajo"32.

La URSS se caracterizaba por los grandes contrastes entre el centro moscovita y la periferia de las repúblicas soviéticas (como pudo comprobar al visitar algunos núcleos de Ucrania, Azerbaiyán y Georgia), con diferentes costumbres, credos y una menor inversión en infraestructuras. Estas apreciaciones rompían con una visión uniforme de la Unión Soviética, en donde se evidenciaban los desequilibrios, y también se matizaban los logros de su modelo económico de progreso, teniendo en cuenta que, según señala Chaves, se mostraba mayor preocupación en la producción e industrialización del país que en el bienestar de los obreros, llegando incluso a contratar expertos foráneos en aras a alcanzar objetivos y obtener beneficios. Si bien las condiciones de vida de los trabajadores habían mejorado, contaban con comedores en sus respectivos centros de trabajo y 'puntos de cultura', en líneas generales, la situación era peor que en occidente. Y la imagen que se perfilaba de ellos era la de obreros disciplinados sujetos a las exigencias del modelo económico soviético.

A cada líder soviético le correspondió un entramado del proyecto de ciudad. Así, en la ciudad del Kremlin, durante la etapa estalinista, se visualizó el triunfo del eclecticismo neoclásico y el ocaso de la utopía revolucionaria. Se tomó la decisión de construir el metropolitano y unir mediante un canal el río

${ }^{31}$ Chaves Nogales, M.; Viaje en avión a Europa. Un pequeño burgués en la Rusia roja; Libros Asteroide; Barcelona; 2012; p. 115.

32 Ibídem; p. 244.

73

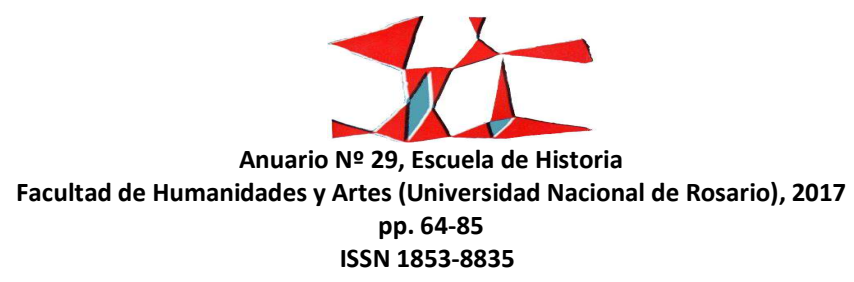


Moscova con el Volga. Se erigieron los edificios estalinianos, reconocibles por sus zócalos de granito, bases firmes, galerías y terrazas con columnas clásicas o inventadas, estrellas, y blasones con alegorías proletarias. También las viviendas de catorce plantas y "las siete torres", concebidas como monumentos conmemorativos de la victoria en la Segunda Guerra Mundial y para celebrar el octavo centenario de la ciudad $^{33}$.

La impresión de esa URSS en construcción que ofrecía al viajero extranjero, según señala Chaves Nogales, era negativa:

“Pero esta impresión, puramente visual, no es absolutamente cierta. De la obra revolucionaria, el viajero no ve más que las resquebrajaduras, las fallas, el albergue incómodo, el tren que no llega, el taxi caro, la falta de urbanización en las calles, la ausencia de confort de las casas, el hacinamiento de los seres en las viviendas, la suciedad de las comidas en los restaurantes cooperativos.. la reconstrucción de la sociedad deshecha por la revolución sobre la base de la dictadura del proletariado escapa a su compresión. Y esta reconstrucción, no terminada aún, es, a pesar de todas las fallas, una obra formidable"${ }^{34}$.

\section{2 "Lo viejo, y lo nuevo", una sociedad fracturada}

Señala Chaves Nogales que la Revolución había removido los cimientos de la sociedad: "el bolchevismo ha arrancado de cuajo todo lo anterior, no ya las instituciones de gobierno, sino las raíces más hondas de la vida privada rusa, los fundamentos de la familia, los estímulos personales, todo"35. Es más, en el ámbito familiar los soviéticos se habían visto sacudidos por el choque entre las tradiciones y las directrices marcadas por el Partido. Los jóvenes mostraban un mayor grado de adaptación a los nuevos tiempos que sus mayores: "En cada habitación, una familia; en cada familia, una guerra viva. El padre es nepman, el hijo comunista; la madre va todos los día a pedir al pope consuelo para sus tristezas"36.

"El padre es nepman...". Los nepmen, pequeños comerciantes, fueron el fruto de la Nueva Política Económica (conocida como NEP por sus siglas en inglés), que promovía una economía híbrida con la que

\footnotetext{
33 Pigariova, Tatiana; Autobiografía de Moscú; Laertes; Barcelona; 200; p. 105; pp. 155-156.

${ }^{34}$ Chaves Nogales, M.; Viaje en avión a Europa...; pp. 245-246.

${ }^{35}$ Ibídem; p. 122.

${ }^{36}$ Chaves Nogales, M.; Viaje en avión a Europa...; pp. 124-125.
}

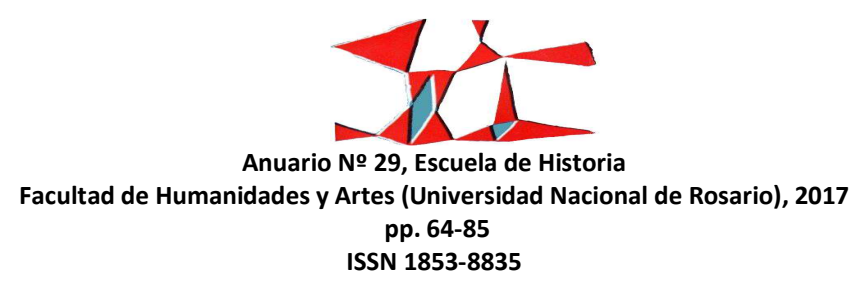




\section{Ecos de la Revolución de octubre en España a tráves del viaje de Chaves Nogales a la Unión Soviética}

paliar los estragos del "comunismo de guerra". Sin embargo, 1928 es un año clave, ya que se produce un viraje en la política económica para iniciar la senda de los planes quinquenales en la industria y de colectivización forzosa en el agro, que llevaría a la industrialización de la Unión Soviética pero con un elevadísimo coste humano.

La madre, en cambio, busca el amparo en la religión, relegada al ámbito de lo privado. Es más, los popes vivían de manera paupérrima, ante la nacionalización de los bienes religiosos y supresión las subvenciones. A pesar de la religiosidad de la población, pues no todos sustituyeron su fe, el pope había perdido el prestigio de antaño ${ }^{37}$.

"El hijo es comunista...". La ruptura familiar queda perfectamente reflejada en las palabras de Chaves, llegando incluso a convertirse estos hijos adoctrinados en delatores de familiares, si éstos no se comportaban conforme a lo estipulado por el Partido Comunista. Resulta ilustrativa a la vez que controvertida la historia Morozov, puesto que hay versiones diferentes. Pavlik tenía 12 años cuando apareció asesinado junto a uno de sus hermanos en1932. Había denunciado a su padre por proporcionar documentos a los kulaks que eran considerados enemigos del pueblo. Su padre les había abandonado y había intereses sobre sus propiedades, de ahí que la muerte pudiera estar motivada por rencillas familiares. No queda tan claro si realmente Pavlik fue pionero, ni su imagen como buen estudiante, al menos, a tenor de su conducta escolar. En el juicio se hallaron los culpables de su asesinato dentro de su entorno familiar. Con independencia de la verdad que subyace a esta historia, todavía difícil de esclarecer ${ }^{38}$, Pavlik Morozov representó un icono moral para los jóvenes. Se erigieron estaturas en su honor, y los Pioneros lo reverenciaron como ejemplo de virtud revolucionaria. Pero más que representar el conflicto entre el "hijo ideal" y el "padre corrupto", se enfatizó el propio sacrificio realizado por Morozov. No obstante, esta imagen fue revisada en 1955, convertido en el número 001 de los integrantes del Konsomol. Otras lecturas de su experiencia se realizaron entre los sectores disidentes que, en vez de mártir, lo convierten en un antihéroe, presentado como un traidor cobarde e ingenuo. Lo cierto es que la historia se fue reinterpretando y amoldando a los intereses del Partido.

\footnotetext{
${ }^{37}$ Ibídem; p. 139.

${ }^{38}$ En ese intento, destacan los estudios de Yury Druzhnikov, Yury; Denouncer No. 001; 1995 y Kelly, Catriona; Comrade Pavlik: The Rise and Fall of a Soviet Boy Hero; Granta Books; London; 2005.
}

75

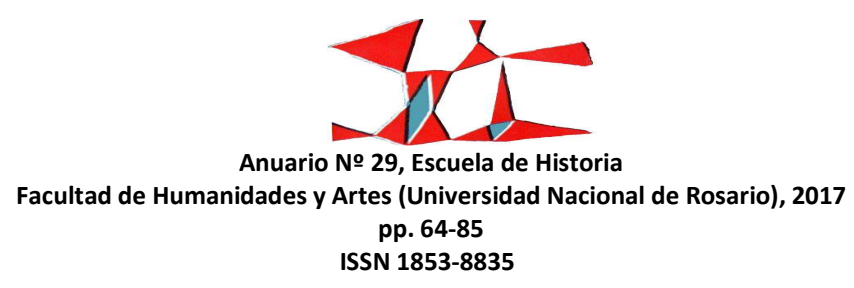


Orlando Figes recoge un testimonio en Los que susurran (2009) que prueba el miedo de los padres a hablar en el ámbito privado:

“Yo jamás hablaba contra Stalin ante mi hijo. Después de la historia de Pavlik Morozov, uno tenía miedo de que se le escapara hasta el menor comentario, incluso frente a los hijos, pues él podía a su vez repetirlo sin querer en la escuela y al enterarse la dirección le preguntaría al niño, -¿dónde escuchaste eso?-. Entonces el niño respondería, -lo dijo papá y papá siempre tiene razón-, y antes de que pudieras darte cuenta te habías metido en graves problemas" ${ }^{\prime 39}$.

En el folleto titulado "Koljós", publicado por los Amigos de la Unión Soviética, se incluye "El hijo del kulak", en el que se narra la denuncia de un hijo A. Tylba hacia sus padres por resistirse a la colectivización agraria ${ }^{40}$. No seguir la pauta marcada por "Ios nuevos tiempos" en la construcción del comunismo implicaba ser etiquetado como "enemigo del pueblo" con el estigma que suponía para individuos y sus respectivas familias. De ahí la moraleja de estas historias.

Respecto a la situación de las mujeres, Chaves mostraba en su obra los cambios acontecidos en materia de derechos en la Rusia soviética. Las mujeres podían votar desde 1918 y obtener el divorcio de mutuo acuerdo, se impulsó la supresión del matrimonio religioso y reconoció el aborto. En la línea defendida por Alexandra Kollontai, integrante del Comité Central del Partido Comunista, en Comunismo y familia (1921). También apuntó a una futura sociedad comunista donde la mujer quedaba redimida de la crianza de los hijos, atendidos por el Estado, pero no vio colmadas todas sus expectativas y acabó formando parte de lo que se conoce como "oposición de izquierdas". Una década más tarde, con el Código Familiar de 1936, que rehabilitó a la familia en la ideología estalinista oficial e ilegalizó el aborto, se imprimía un retroceso a los logros obtenidos ${ }^{41}$.

Chaves Nogales señaló que, a pesar de los avances conseguidos, las mujeres habían sido las más perjudicadas con los cambios:

\footnotetext{
${ }^{39}$ Figes, Orlando: Los que susurran: La represión en la Rusia de Stalin; Edhasa; Barcelona; 2009; p. 207.

${ }^{40}$ Koljos; Publicaciones AUS; Madrid; 1937.

${ }^{41}$ Pérez Garzón, Sisinio; Historia del feminismo; Libros de La Catarata; Madrid; 2012.
}

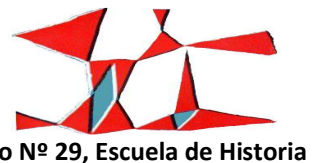




\section{Ecos de la Revolución de octubre en España a tráves del viaje de Chaves Nogales a la Unión Soviética}

“Les han conferido carácter revolucionario, 'prejuicio burgués', arrebatado la educación de sus hijos... ingreso de los comités soviets rurales... Retribución, paro para amamantar, divorcio, pensión alimenticia... pero en cambio otras lo darían todo, las conquistas de la revolución, por un par de medias de seda" 42 .

Algunas de ellas, las más idealistas, que habían cambiado drásticamente de forma de vida lo daban todo por la construcción socialista. Así se ejemplifica a través de la experiencia de una mujer anónima:

“Esta mujer fue de las que tuvieron el famoso carné amarillo de prostituta en la época zarista para poder cursar libremente sus estudios y entregarse a la acción revolucionaria, estuvo después en la emigración, volvió a Rusia el diecisiete y tomó parte en la guerra civil, pero no desempeñando cargo burocrático en la retaguardia, sino echándose al campo como guerrillera al frente de una partida de campesinos adictos al comunismo más por un instinto de conservación, frente a las bandas feroces de Wrangel, Denikin y Kolchack, que por simpatía ideológica con los comunistas. Fueron estas gentes las que en realidad consolidaron el régimen soviético. Cuando éste se impuso, esta mujer no dio por terminada su tarea; fue entonces cuando comenzó la parte más dura, la edificación del comunismo, la reconstrucción económica, ese agotador trabajo cotidiano que se realiza en el seno de las células, los soviets y los sindicatos" ${ }^{\prime 4}$.

Pero la situación era más complicada para las mujeres de la periferia, las que vivían en las repúblicas del Cáucaso, donde tenían una ardua tarea para hacer frente a la tradición y los prejuicios religiosos y con gran tacto, sin atacarlos, ir dándoles la vuelta para que las mujeres pudieran acceder a una mejora de sus condiciones de vida. Estas mujeres extenuadas que habían entregado sus vidas en pos de un ideal revolucionario sirvieron de base para otra obra de Chaves titulada La Bolchevique enamorada (1931). Imagen que también coincide con la que el escritor brinda de otros miembros del Partido comunista que se recomponían de los enormes esfuerzos realizados en la construcción del comunismo en los sanatorios del sur.

${ }^{42}$ Chaves Nogales, M.; Viaje en avión a Europa...; p. 146.

${ }^{43}$ Chaves Nogales, M.; Viaje en avión a Europa...; p. 182.

77

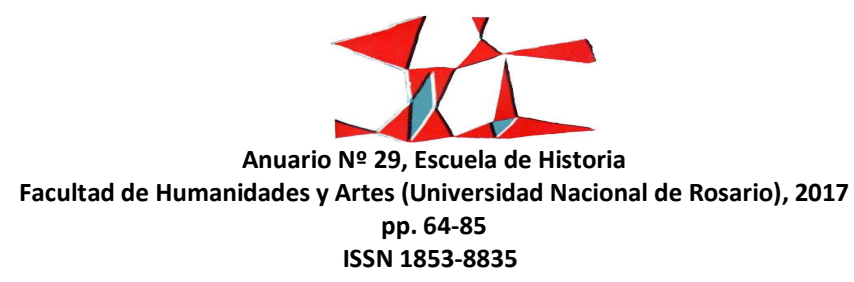


Uno de los aspectos sociales abordados por Chaves Nogales fue el de los jóvenes en desamparo en la URSS. Según el escritor, los niños abandonados y sin hogar, "crecen como fieras" atenazados por el hambre y el frío a finales de los años veinte. Esta descripción coincide con los besprizorniki, reconocibles por los signos visibles de sus vidas depauperadas, que impelidos por la situación delinquían para obtener comida. Su presencia se remontaba a tiempo atrás, algunos habían migrado de la región del Volga, donde fue especialmente pertinaz la hambruna de 1921. Si al principio fueron considerados como víctimas del sistema previo y el Estado actuó para atenderles y educarles conforme a los nuevos valores, posteriormente y debido a su incremento, fueron recluidos en lugares especiales, pero el problema no cesó, ya que se trataba de nuevos jóvenes. Más que huérfanos a consecuencia de los efectos de la guerra civil rusa o la hambruna, se les consideró fruto de una incorrecta educación y de ahí que la visión de los mismos tornara de jóvenes desamparados a la de delincuentes ${ }^{44}$, justo el contra modelo del ejemplo representado por Pavlik Morozov, por tanto, se les aplicaba el código soviético. Uno de los efectos del mismo fue la división de la sociedad entre la "aristocracia del Partido" y el resto.

Las familias procuraban recomponerse y adaptarse a los nuevos tiempos, no sin sacrificios. No todos los soviéticos pertenecían al Partido, pues los militantes eran minoría respecto al conjunto de la sociedad. Además, tampoco tener carné les confería inmunidad para no caer en desgracia. Y es precisamente en la etapa estalinista cuando la represión tuvo su máximo exponente ${ }^{45}$. Sin embargo, Chaves Nogales no constató rebeldía, sino una generación de jóvenes que no concebía la existencia fuera del régimen comunista. La causa de ello estriba probablemente por los efectos del adoctrinamiento y la aplicación de medidas represivas ${ }^{46}$.

\subsection{La política represiva}

La policía política, la GPU, actuaba eficazmente. Chaves Nogales en su viaje presenció el viraje de la política estalinista en la desconsideración hacia los "nepmen". Estos pequeños comerciantes que procuraban salir a flote y eran representativos de la Nueva Política Económica que llegaba a su fin eran vilipendiados por el régimen:

\footnotetext{
${ }^{44}$ Pilkington, Hilary; Russia's Youth and its Culture; Routledge, London \& N.Y.; 1994; pp. 60-64.

${ }^{45}$ Kotek, J. Rigoulot, P.; Los campos de la muerte: cien años de explotación y exterminio; Salvat; 2001.

${ }^{46}$ Chaves Nogales, M; Viaje en avión a Europa...; p. 239.
}

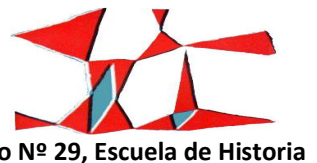




\section{Ecos de la Revolución de octubre en España a tráves del viaje de Chaves Nogales a la Unión Soviética}

"cuando abre su tiendecita no sabe qué nueva calamidad va a traerle el nuevo día. Puede esperar que de un momento a otro le confisquen sus pobres géneros, le insulte la muchedumbre o le encarcelen agentes de la GPU. El comerciante este pequeño y humilde hombre de la tiendecita, es el paria de la Rusia soviética" ${ }^{47}$.

Es más, se les iba estrechando el cerco, ya que tenían menos derechos que el resto de ciudadanos soviéticos como el voto, se negaba a sus hijos el acceso a las universidades y se les cargaba con tributos. Pero no solo debía hacer frente a esas dificultades, al lado de cada tiendecita, el Estado podía abrir un establecimiento cooperativo más competitivo por la exención de impuestos y las ventajas de la protección oficial $^{48}$.

Respecto a los líderes revolucionarios que cayeron en desgracia como Trotsky, comprobó que no había modo de "encontrar un retrato en toda Rusia" ${ }^{49}$, evidenciando esa eliminación en las imágenes y de la propia historia de la Rusia soviética, país al que ayudó construir. Esa misma apreciación la realizó también el notario Diego Hidalgo en su viaje a la URSS ${ }^{50}$. Stalin consiguió sustentar el poder empleando la represión política contra los elementos de oposición dentro del Partido. En principio, la maquinaria represiva había servido de base para eliminar a los oponentes, pero se hizo extensiva a miembros del Politburó como Trostky, Zinoviev y Kamenev, expulsados del partido en 1927. Después le tocó el turno a la "oposición de derechas" entre los que se encontraba Bujarin por su crítica a la política de colectivización forzosa y rápida industrialización a expensas del campesinado. Stalin consiguió eliminar a la potencial oposición a su liderazgo a la altura de 1934 y después procedió a una gran purga del partido que tuvo su momento álgido en 1937. Frente a otras orientaciones, ya fuese desde la oposición de izquierda o de derecha, Stalin disponía de la máquina del partido, sobre todo, de la GPU. El triunfo de Stalin sobre Trotsky fue, aseguró Chaves Nogales, principalmente un triunfo policiaco más que en el plano de las ideas ${ }^{51}$. Sobre esta praxis, David

\footnotetext{
47 Ibídem; p. 140.

${ }^{48}$ Ibídem; p. 141.

49 Ibídem; p. 205.

${ }^{50}$ Hidalgo, Diego; Un notario español en Rusia; Alianza; Madrid; 1985; p. 146. Publicado por primera vez en la editorial Cénit en 1929.

${ }^{51}$ Chaves Nogales, Manuel; Viaje en avión a Europa...; p. 215.
}

79

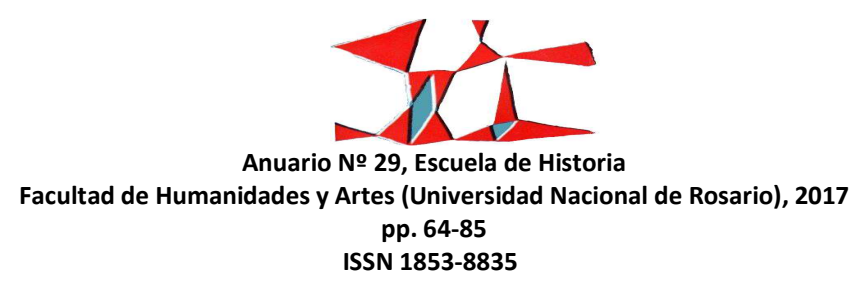


Sheerer ha señalado que la represión se convirtió en un elemento constitutivo de la construcción del Estado durante la década de $1930^{52}$.

A diferencia de Trostky, ya caído en desgracia, Chaves Nogales apreció la buena imagen de Kalinin, más que un campesino, jefe del Estado, presidente de la URSS, arquetipo del régimen por su origen humilde ${ }^{53}$. No obstante, para mantener en toda su pureza el ideal comunista, sería preciso, según el escritor, hacer una revolución cada cinco años, puesto que el comunista mismo, por grande que sea la pureza de su ideario, al poco tiempo de estar dedicado a la labor gubernamental, cae en un oportunismo político que le aleja fatalmente de los objetivos de la revolución. Así se había creado esa burocracia del partido, que actuaba como formidable conservador ${ }^{54}$. En efecto, la centralización e hiperburocratización del sistema fueron lacras, como también los efectos de la corrupción.

En el ámbito cultural también quedó reflejado el férreo control del régimen estalinista. Así, Fernando De los Ríos, en Mi viaje a la Rusia sovietista, señaló la censura en las bibliotecas y centros de enseñanza, la propaganda de los libros de texto utilizados en las escuelas y el dogmatismo del sistema educativo, cultural y periodístico destinado a ofrecer una interpretación de los acontecimientos, la oficial ${ }^{55}$. Por su parte, el notario Diego Hidalgo se asombraba del dominio de conocimientos de muchos ciudadanos soviéticos, es más, apuntó a la cultura como verdadera "piedra filosofal del comunismo" y de ahí los esfuerzos por ilustrar, aunque bajo los límites impuestos por el partido ${ }^{56}$. Mientras Chaves Nogales incidió en el papel de la prensa en la Unión Soviética, destacando su falta de libertad y sometimiento, atribuyéndole el papel de "arma de combate" absolutamente inerme por sí sola, de la que disponía el Poder como disponía de las ametralladoras o de los carros de asalto. Los periódicos murales, que habían servido como medio para manifestar las opiniones y las críticas, iban en retroceso y cada vez los soviéticos acudían menos con sus quejas a estas tablillas que antes llenaban a diario con sus escritos. De lo que pasaba en el extranjero, el ciudadano de la URSS no tenía más noticias que las que le facilitaban los boletines oficiales del

\footnotetext{
52 Shearer, David; "Stalinist Repression, Modernity, and the Social Engineering Argument", in Harris, James; The Anatomy of Terror: Political Violence under Stalin; Oxford University Press; Oxford; 2013. El autor examina hasta qué punto las políticas de represión masiva pueden llamarse ingeniería social o simplemente políticas reactivas violentas de un régimen que se desplaza de una crisis propia a otra.

${ }^{53}$ Chaves Nogales, Manuel; Viaje en avión a Europa...; pp. 211-214.

54 Ibídem; pp. 214-215.

55 De los Ríos, Fernando; Mi viaje a la Rusia sovietista; 1970; p. 152.

56 Hidalgo, Diego; Un notario español en Rusia...; pp. 89, 109 y 111.
}

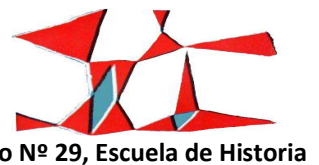




\section{Ecos de la Revolución de octubre en España a tráves del viaje de Chaves Nogales a la Unión Soviética}

comisariado de Negocios Extranjeros. La incomunicación del pueblo con el resto del mundo era considerable, salvo acontecimientos que pudieran interpretarse en clave revolucionaria. No obstante, la labor periodística continuaba en el plano formal con apariencia de libertad.

En conclusión, para Chaves Nogales todo lo que se decía sobre los terroríficos medios represivos del Gobierno de Moscú, de la tiranía del partido comunista, de los manejos inquisitoriales de la Policía Soviética, era cierto. Incluso en la constitución rusa no aparecía referencia a los derechos del Hombre; sólo se encontraba presidiendo la constitución del Estado la "Declaración de los derechos del pueblo trabajador y explotado" ${ }^{\prime 57}$. Y no todos accedían al trabajo o al Partido, de ahí las diferencias entre los propios soviéticos formándose una aristocracia, la de la nomenclatura. Los efectos de la represión supusieron un daño irreparable para las víctimas y sus familiares. En un momento posterior, los represaliados pudieron acceder a la rehabilitación a raíz del XX Congreso del PCUS de 1956, es decir, durante el deshielo de Jrushchov, aunque de manera limitada. A raíz de la glasnost, aplicada en tiempos de Gorbachov, comenzó a salir a la luz documentación de archivos soviéticos y tomaron forma los distintos casos personales que lograron la rehabilitación. Destacó en esta labor Vitali Shentalinski desvelando el estrecho marcaje al que eran objeto los escritores por la Policía Política y las penalidades sufridas por un colectivo a quienes se les había robado las palabras y su sustento ${ }^{58}$.

\section{A modo de conclusión}

La mitificación y la crítica al régimen soviético convivieron en España y se reflejó en las crónicas periodísticas, a través de manifestaciones culturales y propagandísticas de los distintos colectivos sociopolíticos hasta que el desenlace de la contienda fratricida en 1939 marcó una línea anticomunista, la seguida por la dictadura franquista. Ésta jugó un papel a favor del bloque occidental en un nuevo escenario internacional de guerra fría, a través de los pactos de 1953 con Estados Unidos y como integrante de foros supranacionales. De ahí que el efecto de los años de dictadura en la historiografía española fueron los derivados de la censura, la reproducción de la historiografía foránea y textos monocordes que seguían una línea más propagandística que científica. El debate se abrió en la Transición política a la democracia, aunque

\footnotetext{
${ }^{57}$ Chaves Nogales, M.; Viaje en avión a Europa...; p. 242.

${ }^{58}$ Shentalinski, V.; Esclavos de la libertad: Los archivos literarios del KGB; Denuncia contra Sócrates: Nuevos descubrimientos en los archivos; Galaxia Gutenberg; Barcelona; 2006 y Crimen sin castigo: Últimos descubrimientos en los archivos literarios del KGB; Galaxia Gutenberg; Barcelona; 2007.
}

81

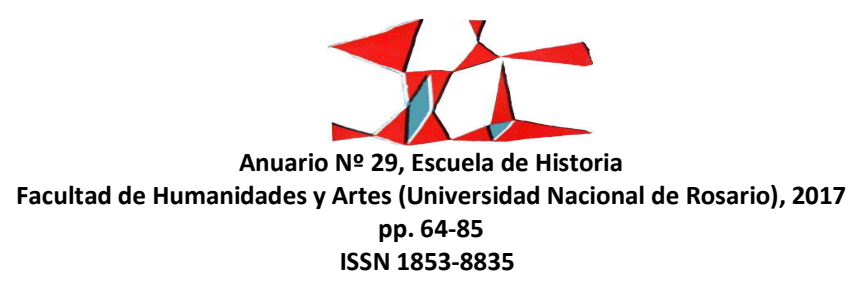


con dificultades debido a las barreras idiomáticas y la falta de recursos en la investigación, pero nuevamente se reprodujo una polifonía de visiones contrapuestas y proliferaron temas de historia contemporánea abordados libremente. Un interés editorial renovado se produjo con la llegada de la Perestroika y la inesperada caída de la URSS. La obra reeditada de Chaves Nogales sobre Rusia es una 'voz recuperada' del exilio. Como cronista de su tiempo, señalaba uno de los principales defectos reiterados en las percepciones sobre la Rusia soviética:

“(...) desde el comunismo o el anticomunismo, estar atentos al desenvolvimiento de los hechos, pensando y sopesando las responsabilidades de cada uno de los factores que han intervenido en la terrible experiencia que se está haciendo en la carne viva de un pueblo de ciento cuarenta millones de habitantes, sin desechar la posibilidad del alumbramiento de una nueva humanidad, pero sin perder de vista al mismo tiempo que puede haberse errado la senda"59.

Sus palabras prevenían de las visiones tendenciosas para fijar la vista en los múltiples factores y en el desenvolvimiento de los mismos, interpelación que no ha de caer en saco roto. En su interpretación sobre la realidad soviética a la altura de 1928, el autor consideraba que en la edificación del comunismo en la Unión Soviética se había hecho a costa de las teorías comunistas, quedándose en un capitalismo de Estado, fomentado el nacionalismo que había relegado sus miras expansionistas, y se había erigido una aristocracia, la del Partido, evidenciándose la transformación radical y las propias fisuras de ese edificio en la sociedad soviética, extenuada en esa construcción, vigilada y disciplinada. A pesar de todos los fallos observados, afirmaba que esa reconstrucción una obra formidable, pues se daba el caso que hasta quienes no eran bien considerados por el régimen soviético "se levantarían si estuviera en peligro", pues ese nuevo orden significaba también:

“la paz, el orden, el fomento de la riqueza nacional, la garantía de la independencia nacional... Y la gran masa social que ama estas cosas por encima de todo cierra los ojos ante la doctrina comunista, procura eludir sus consecuencias, se pliega todo lo posible a la voluntad de los gobernantes y, en definitiva, los apoya" ${ }^{60}$.

\footnotetext{
${ }^{59}$ Chaves Nogales, M.; Viaje en avión a Europa...; p. 248.

${ }^{60}$ Ibídem; p. 237
}

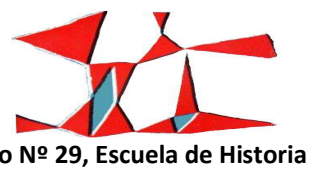




\section{Ecos de la Revolución de octubre en España a tráves del viaje de Chaves Nogales a la Unión Soviética}

Sus impresiones en el año en el que se cumple el primer centenario de la revolución de Octubre sirven para profundizar en la imagen proyectada por unos países en otros. Los libros de viaje sobre la Unión Soviética en los años veinte y treinta mostraron el interés en el devenir de un proceso histórico y sus claroscuros, supusieron un avance en los estudios sobre Rusia.

Dentro de las aportaciones historiográficas desde España faltan trabajos de síntesis y revisión acerca de lo publicado sobre Rusia, así como investigaciones fruto de fuentes inéditas y una aproximación interdisciplinar que aporten una visión más amplia y ajustada del país eslavo y la proyección internacional del modelo soviético en los más diversos ámbitos que desmonten la visiones propagandísticas. El debate sigue abierto en encuentros científicos, monográficos en revistas especializadas, movilizadas por efemérides, cuyos frutos permitirán una actualización de los estudios sobre la Revolución y la Unión Soviética, cuyo legado sigue visible no sólo en ciertas praxis políticas y en el "homo sovieticus"61, las generaciones que han vivido bajo su modelo y legado cultural, sino que también resulta importante para comprender el devenir de la Revolución de Octubre y el siglo XX.

\section{Bibliografía Citada}

Aleksiévich, S.; El fin del homo sovieticus; El Acantilado; Barcelona; 2015.

Almuiña, Celso J.; “La imagen de la Revolución rusa en España”; IH; 17 ; 1997; p. 217.

Andrade, J. y Hernández, F. (eds); 1917. La Revolución rusa cien años después; Akal; Madrid; 2017.

Avilés, Juan; La fe que vino de Rusia; UNED; Madrid; 1999.

Blanco García, Carmen; "Sofía Casanova e Emma Goldman na revolución rusa"; en Pazos, Antón M.; Vida e tempo de Sofía Casanova (1861-1958); 2010, pp. 115-133.

Carantoña, Francisco y Puente, Gustavo (Eds); La Revolución Rusa 70 años después: Actas del Segundo Coloquio de Historia Contemporánea; Universidad de León, León; 1988.

Díez, F.; La revolución rusa; Anaya; Madrid; 1991; también autor de Lenin. Una biografía; El viejo Topo; Madrid; 1999. Fernández, A.; La Revolución Rusa; Istmo; Madrid; 1990.

Egido, Ma Ángeles; “Del paraíso soviético al peligro marxista: La Unión Soviética en la España republicana (1931-1936)"; Cuadernos de Historia Contemporánea; 10; 1988; pp. 139-154.

${ }^{61}$ Aleksiévich, S.; El fin del homo sovieticus; El Acantilado; Barcelona; 2015.

83

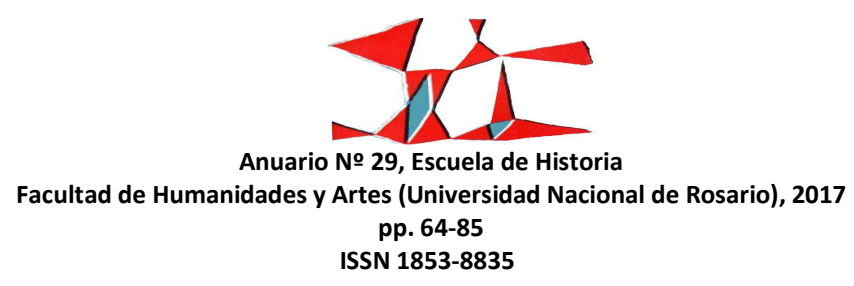


Elorza, Antonio y Bizcarrondo, Marta; Queridos camaradas. La Internacional Comunista y España; Planeta; Barcelona; 1999.

Fernández, A.; "Auge y caída del comunismo"; Cuadernos de Historia Contemporánea, 21; 1999; pp 107-146.

Figes, Orlando: Los que susurran: La represión en la Rusia de Stalin; Edhasa; Barcelona; 2009; p. 207.

Fontana, J.; "la Revolución Rusa y nosotros"; Nuestra Historia, 2; 2016; pp. 155-163. Autor del libro El siglo de la revolución. Una historia del mundo desde 1914; Crítica; Barcelona; 2017.

Forcadell, C. y Carreras Ares, J. J.; Parlamentarismo y bolchevización: el movimiento obrero español, 19141918; Crítica; Barcelona; 1978.

Garrido, M.; Compañeros de viaje. Historia y memoria de las Asociaciones de Amistad Hispano-Soviéticas; Editum; Murcia; 2009.

Hermida, C.; La revolución bolchevique no fue un golpe de Estado; Historia y Comunicación Social; 7; 2002; pp.109-119.

Hernández, F.; Guerra o revolución. El partido comunista de España en la Guerra Civil; Crítica, Barcelona; 2010.

Lazo Díaz, Alfonso; La Revolución Rusa en el diario $A B C$ de la época; Secretariado de Publicaciones de la Universidad de Sevilla; Sevilla; 1975.

Meaker, Gerald H.; La izquierda revolucionaria en España 1914-1923; Ariel; Barcelona; 1978. Cruz, R.; EI Partido Comunista de España en la Il República; Alianza; Madrid; 1987.

Pabón, J.; Bolchevismo y literatura. La novela soviética en sus creaciones típicas; Madrid; 1949.

Paniagua Fuentes, F. J.; "Las repercusiones de la revolución rusa en el movimiento libertario español"; Anales del centro de Alzira de la UNED, 1; 1980; pp 61-88.

Pelloile, Manuelle; "La imagen de la Revolución Rusa en España: amplificación y permanencias años veintenoventa del siglo XX"; en Civil, P. y Crémoux, F. Actas del XVI Congreso de la Asociación Internacional de Hispanistas: Nuevos caminos del hispanismo; París, del 9 al 13 de julio de 2007; Vol. 2; 2010.

Pérez Garzón, Sisinio; Historia del feminismo; Libros de La Catarata; Madrid; 2012

Pérez Ledesma, M. y Cruz, R.; Cultura y movilización en la España contemporánea; Alianza; 1997.

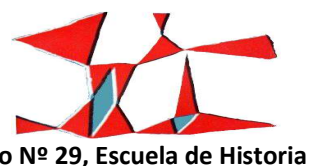

Facultad de Humanidades y Artes (Universidad Nacional de Rosario), 2017

pp. 64-85

ISSN 1853-8835 


\section{Ecos de la Revolución de octubre en España a tráves del viaje de Chaves Nogales a la Unión Soviética}

Rodríguez, A.; La revolución rusa y el desarrollo de la URSS; Akal; Madrid; 1991. Martín, R. M.; "La revolución soviética y su impacto internacional. La URSS 1917-1929"; en Pereira, J.C. (Coord.). Historia de las relaciones internacionales contemporáneas; Ariel; Barcelona; 2001; pp 263-279.

Romero, F.; The Foundations of Civil War. Revolution, Social Conflict and Reaction in Liberal Spain, 19161923; Cañada Blanch Centre; London; 2008.

Sánchez Pita, Fernando; “El viaje que retrató a la Rusia de 1917"; Archivamos: Boletín ACAL; 87; 2013; p. 4748.

San Román Sevillano, A.; Los amigos de la Unión Soviética (AUS) [Microforma]: propaganda política en España (1933-1938); Ediciones Universidad de Salamanca; Salamanca; 1994.

Santonja, G.; Del lápiz rojo al lápiz libre. La censura de prensa y el mundo del libro; Barcelona; 1986.

Sanz Guitián, Pablo; Viajeros españoles en Rusia; Compañía Literaria; Madrid; 1995.

Shearer, David; "Stalinist Repression, Modernity, and the Social Engineering Argument", in Harris, James; The Anatomy of Terror: Political Violence under Stalin; Oxford University Press; Oxford; 2013.

Shentalinski, V.; Esclavos de la libertad: Los archivos literarios del KGB; Denuncia contra Sócrates: Nuevos descubrimientos en los archivos; Galaxia Gutenberg; Barcelona; 2006 y Crimen sin castigo: Últimos descubrimientos en los archivos literarios del KGB; Galaxia Gutenberg; Barcelona; 2007.

Trinidad Pérez, Francisco; El Movimiento Obrero en la provincia de Cádiz (1914-1923); Universidad de Cádiz; Cádiz; 1998.

Vázquez Liñán, M.; La Revolución y la Guerra civil rusa en "El maestro Juan Martínez que estaba alli"; en Bellido, P. y Cintas, Mạ I. (Coords); Manuel Chaves Nogales, una aproximación; 2009; p. 65-83.

Vázquez, M.; Propaganda y política de la Unión Soviética en la Guerra Civil Española (1936-1939); Universidad Complutense de Madrid; Madrid; 1999. Kowalsky, D.; La Unión Soviética y la guerra civil española: una revisión crítica; Crítica; Barcelona; 2004.

Viñas, Á.; El escudo de la República. El oro de España, la apuesta soviética y los hechos de mayo de 1937; Crítica; Barcelona; 2007 y El honor de la República. Entre el acoso fascista, la hostilidad británica y la política de Stalin; Crítica; Barcelona; 2008.

Yury Druzhnikov, Yury; Denouncer No. 001; 1995 y Kelly, Catriona; Comrade Pavlik: The Rise and Fall of a Soviet Boy Hero; Granta Books; London; 2005.

Recibido: 8 de mayo de 2017

Aceptado: 27 de julio de 2017

Versión Final: 22 de septiembre de 2017

85

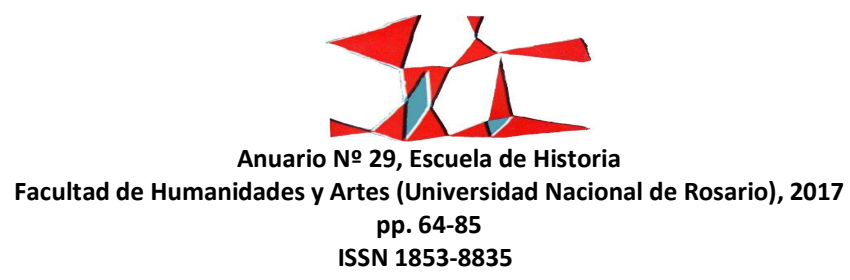

